\title{
Commentary Death by acid rain: VAP or EXIT?
} Kentigern Thorburn ${ }^{1,2}$ and Andrew Darbyshire ${ }^{1}$

\begin{abstract}
${ }^{1}$ Department of Paediatric Intensive Care, Royal Liverpool Children's Hospital - Alder Hey, Liverpool, L12 2AP, UK
${ }^{2}$ School of Host Defence and Infection, The University of Liverpool, Liverpool, L69 7ZX, UK
\end{abstract}

Corresponding author: Kentigern Thorburn, kent.thorburn@alderhey.nhs.uk

Published: 2 December 2009

Critical Care 2009, 13:1008 (doi:10.1186/cc8169)

This article is online at http://ccforum.com/content/13/6/1008

(c) 2009 BioMed Central Ltd

See related research by Abdel Gawad et al., http://ccforum.com/content/13/5/R164

\begin{abstract}
Ventilator-associated pneumonia (VAP) is a new (nosocomial) lower respiratory tract infection diagnosed in mechanically ventilated patients 48 or more hours after intubation. There is no gold standard for establishing the diagnosis and its pathogenesis is iatrogenic and multifactorial. Gastro-oesophageal reflux is common in mechanically ventilated children, but its role in VAP remains speculative. VAP is associated with increased mortality and morbidity, prolonged duration of ventilation and hospital stay, and escalated costs of hospitalisation. VAP 'bundles' are championed as the antidote.
\end{abstract}

Ventilator-associated pneumonia (VAP) is defined as a new (nosocomial) lower respiratory tract infection diagnosed in mechanically ventilated patients $\geq 48$ hours ('early-onset' VAP) or $\geq 4$ days ('late-onset' VAP) after intubation [1-5]. Management of early-onset and late-onset VAP may differ as the causative factors and likely pathogens will influence treatment strategies, such as antimicrobial therapy $[2,3,5]$. VAP is associated with increased mortality and morbidity, prolonged duration of ventilation and hospital stay, and escalated costs of hospitalisation [2,3,5-9]. In resource-rich countries VAP is reported to be the second most common nosocomial/hospital-acquired infection in pediatric and neonatal intensive care units, with incidences ranging from 3 to $30 \%$ and VAP-attributable mortality rates up to $20 \%$ $[5,7,9]$. The potential devastating impact of VAP is emphasized by the study of Abdel Gawad and colleagues [1] where a $50 \%$ incidence of VAP and $70 \%$ mortality with VAP means that more than $80 \%$ of all the deaths in their unit were due to hospital-acquired infection/VAP.

Defining VAP is the easy aspect, making the correct diagnosis (let alone confirmation) becomes more challenging, and establishing universally accepted criteria is a distant goal.
There is no gold standard. The Clinical Pulmonary Infection Score (CPIS), utilized in the study by Abdel Gawad and colleagues, is based on five clinical parameters - fever, leucocytosis, purulence of secretions, oxygenation, extent of radiographic infiltrates - and strengthened by cultures from the lower respiratory tract (most often broncho-alveolar lavage $(B A L)$ ) [10]. It suffers from poor inter-rater agreement and retrograde influence from positive BAL results [11]. The current reference standard (read 'gold standard') comprises the clinical criteria for the diagnosis of VAP established by the National Nosocomial Infection Surveillance (NNIS) system of the Centers for Disease Control and Prevention (CDC), which incorporate age-specific criteria [4]. They do not require microbiological confirmation to diagnose pneumonia. The CDC/NNIS criteria also suffer from inter-rater inconsistency. Additionally, the recurrent question as to whether positive BAL cultures reflect true infection or merely bacterial colonization lingers. Moreover, many studies show weak concordance between designated diagnostic criteria and clinical diagnosis of VAP by 'experts' $[5,7,8,12]$. To further muddy the waters, the 'Big-Brother' effect of mandatory reporting of health care-associated infections in many countries and penalties for underperformance complicates interinstitutional comparisons by blunting diagnostic accuracy.

The pathogenesis of VAP is iatrogenic and multifactorial, with major factors being: the endotracheal tube facilitating microbial access to the lung and providing a nidus for growth of biofilm-encased bacteria; micro-aspiration from oropharynx or gastrointestinal tract; extension of existing micro-infection (foci of localized micro-infection causing local bronchiolitis without clinically relevant pneumonia that proceed to develop into macro-bronchopneumonia); blood-borne transmission from other sites; and inhalation/instillation of contaminants

$\mathrm{BAL}=$ broncho-alveolar lavage; $\mathrm{CDC}=$ Centers for Disease Control and Prevention; EXIT = exogenous infection transmission; GER $=$ gastrooesophageal reflux; NNIS = National Nosocomial Infection Surveillance; VAP = ventilator-associated pneumonia. 
(for example, aerosols or cross-infected suction catheters) $[2,5,8,9,13]$. Endogenous community-acquired pathogens are generally responsible for early-onset and nosocomial microbes residing in oropharyngeal or gastric contents for late-onset VAP.

Abdel Gawad and colleagues [1] confirmed that gastro-oesophageal reflux (GER) is common in mechanically ventilated children [14]. The authors demonstrated reflux of alkaline or acidic gastric fluids into the lower half of the oesophagus $\mathrm{pH}$ probe positioned $5 \mathrm{~cm}$ above the gastro-oesophageal sphincter), but have not demonstrated gastric fluid in the oropharynx or bronchial tree. Neither have they shown changes in $\mathrm{pH}$ or gastric pepsin in the bronchial tree to support their inference of gastro-pulmonary spill-over. A high incidence of GER in both VAP and non-VAP patients, along with small sample size, restricts the association of GER with VAP to speculation. A lack of reported data concerning surveillance cultures from the oropharynx and gastro-intestinal tract also curtail support for a gastro-pulmonary route of VAP infection. The paucity of these data additionally prevents understanding whether the VAP is endogenous or exogenous in origin. The low incidence of BAL culture identifying Staphylococcus aureus would suggest a low rate of endogenous VAP. The high incidence of Klebsiella and Acinetobacter (especially if multi-resistant organisms) implies exogenous infection transmission (EXIT) and/or late-onset VAP. Surprisingly, no polymicrobial cultures were reported. Polymicrobial cultures are well-described in other studies $[5,6,13]$.

The most compelling data are the association of acidic reflux with VAP and especially death [1]. This finding is directly contrary to the concept that the acidification of gastric contents inhibits colonization with potentially pathogenic bacteria $[5,15]$. If we are to believe that acidic reflux led to gastro-pulmonary acidic rain-out, what were the mechanisms that led to death? Hypotheses include: bronchial mucosal and/or lung parenchymal damage by acid and pepsin; neutralisation of pulmonary macrophages by gastric acid rain; enhanced bacterial colonization of denuded aerodigestive tract surfaces by potential pathogens.

Perhaps acidic GER reflects worsening disease severity and is thereby related to death. Possibly there is no pulmonary impact from presumed gastric acid rain-out, and most likely EXIT is the key factor with cross-contamination of intubated patients from an external (to the patient) multi-resistant source. Certainly the high VAP incidence of $50 \%$ and accompanying mortality of $70 \%$ reported by Abdel Gawad and colleagues [1] is troubling. Even if it is a matter of death with VAP rather than death from VAP, the answer to this unit's problem must lie with the introduction of VAP prevention strategies or 'VAP bundles' $[5,8,9]$, concentrating on the basic modifiable risk factors rather than medicinal options and certainly not escalating antibiotic sophistication.
VAP prevention strategies concentrate on education, minimising invasive mechanical ventilation and reducing airway contamination from endogenous (oropharynx, gastric, and sputum retention) and exogenous sources (EXIT). Abdel Gawad and colleagues reiterate the brutal reality that the Grim Reaper remains a close friend of VAP.

\section{Competing interests}

The authors declare that they have no competing interests.

\section{References}

1. Abdel Gawad TA, El-Hodhod MA, Ibrahim HM, Michael YW: Gastroesophageal reflux in mechanically ventilated pediatric patients and its relationship to ventilator-associated pneumonia. Crit Care 2009, 13:R164.

2. Valles J, Pobo A, Garcia-Esquinol O, Marsical D, Ral T, Fernandez R: Excess ICU mortality attributable to VAP: the role of early and late onset. Intensive Care Med 2007, 33:1363-1368.

3. Diaz E, Munoz E, Agbaht K, Rello J: Management of ventilatorassociated pneumonia caused by multi-resistant bacteria. Curr Opin Crit Care 2007, 13:45-50.

4. Foglia E, Meier MD, Elward A: Ventilator-associated pneumonia in neonatal and pediatric intensive care unit patients. Clin Microbiol Rev 2007, 20:409-425.

5. Centers for Disease Control and Prevention. Criteria for Defining Nosocomial Pneumonia [http://www.cdc.gov/ncidod/ hip/NNIS/members/pneumonia/Final/PneumoCriteriaV1.pdf]

6. Srinivasan R, Asselin J, Gildengorin G, Weiner-Kronish J, Flori HR: A prospective study of ventilator-associated pneumonia in children. Pediatrics 2009, 123:1108-1115.

7. Gauvin F, Dassa C, ChaibouM, Proulx F, Farrell CA, Lacroix J: Ventilator-associated pneumonia in intubated children: comparison of different diagnostic methods. Pediatric Crit Care Med 2003, 4:437-443.

8. Morrow BM, Argent AC, Jeena PM, Green RJ: Guideline for the diagnosis, prevention and treatment of paediatric ventilatorassociated pneumonia. South African Med J 2009, 99:255267.

9. Bigham MT, Amato R, Bondurrant P, Fridriksson J, Krawczeski CD, Raake J, Ryckman S, Schwartz S, Shaw J, Wells D, Brilli RJ: Ventilator-associated pneumonia in the pediatric intensive care unit: characterizing the problem and implementing a sustainable solution. J Pediatrics 2009, 154:582-587.

10. Pugin J, Auckenthaler R, Mili N, Janssens JP, Lew PD, Suter PM: Diagnosis of ventilator-associated pneumonia by bacteriologic analysis of bronchoscopic and nonbronchoscopic 'blind' bronchoalveolar lavage fluid. Am Rev Respir Dis 1991, 143: 1121-1129.

11. Luyt CE, Chastre J, Fagon JY: Value of the clinical pulmonary infection score for the identification and management of ventilator-associated pneumonia. Intensive Care Med 2004, 30: 844-852.

12. Labenne M, Poyart C, Rambaud C, Goldfarb B, Pron B, Jouvert P, Delamere C, Sebag C, Hubert P: Blind protected specimen brush and bronchoalveolar lavage in ventilated children. Crit Care Med 1999, 27:2537-2543.

13. Rea-Neto A, Youssef NC, Tuche F, Brunkhorst F, Ranieri VM, Reinhart K, Sakr Y: Diagnosis of ventilator-associated pneumonia: a systematic review of the literature. Crit Care 2008, 12:R56.

14. Hue V, Leclerc F, Gottrand F, Martinot A, Crunelle V, Riou Y, Deschildre A, Fourier C, Turck D: Simultaneous tracheal and oesophageal $\mathrm{pH}$ monitoring during mechanical ventilation. Arch Dis Child 1996, 75:46-50.

15. Methany NA, Clouse RE, Chang Y: Tracheobronchial aspiration of stomach contents in critically ill tube-fed patients: frequency, outcomes and risk factors. Crit Care Med 2006, 34: 1007-1015. 